\title{
Socket-shield Technique and Immediate Implant Placement for Ridge Preservation: Case Report Series with 1-year Follow-up
}

\author{
Rola A Habashneh ${ }^{1}$, Maher A Walid², Tahani Abualteen ${ }^{3}$, Mohammad Abukar ${ }^{4}$
}

\begin{abstract}
Aim: To evaluate the role of socket-shield technique for ridge preservation in immediate implant placement sites.

Background: The socket-shield technique seems to be beneficial for ridge preservation despite its insufficient documentation. In this case report series, implants were placed immediately after extracting a hopeless teeth using this technique and then were followed up for 1 year to document functional and esthetic outcomes.

Cases description: Five patients presented with a non-restorable teeth were treated using the socket-shield protocol and immediate implant placement. Roots were dissected in a mesiodistal direction along the long axis down to the apex; a periotome was later used to detach the palatal fragment of the root, while keeping the buccal one. Following sequential osteotomy drilling, implants were placed. The gap between the implant and the shield was filled with a synthetic bone grafting material. A customized healing abutment with an S-shaped emergence profile was prepared to support a coronal emergence profile of the tooth. Patients had follow-up visits after 6 weeks and 5 or 6 months before proceeding to prosthetic reconstruction phase. Screw-retained porcelain fused to metal crowns and titanium abutments were inserted intraorally with $35 \mathrm{~N} \mathrm{~cm}$ torque and screw-access holes were restored.

Conclusion: The socket-shield technique along with immediate implant placement is a minimally invasive approach that can preserve the hard and soft tissue contour of the ridge and can be implemented in areas of high esthetic demands for better esthetic outcomes.
\end{abstract}

Keywords: Immediate implant, Ridge preservation, Socket-shield technique.

The Journal of Contemporary Dental Practice (2019): 10.5005/jp-journals-10024-2642

\section{INTRODUCTION}

Using a single implant crown is a viable and practical treatment option for single-tooth replacement. ${ }^{1,2}$ This treatment option has had evidence-based success over a 5-year period since 1996. Protocols of prosthodontic procedures for single implant crowns were first published in the 1980s, but a reference was made to the first single implant crown in $1986 .^{3}$ Implants are often recommended over fixed partial dentures because (1) preparation and hypersensitivity of adjacent teeth is avoided, ${ }^{4}(2)$ preservation of vitality of adjacent teeth is maintained, ${ }^{4}$ (3) implants are highly predictable and require little maintenance, (4) implants preserve ridge height and width, ${ }^{5}$ and (5) implants enhance gingival response and improve access for oral hygiene.

On the basis of the International Team for Implantology's (ITI) and their (SAC) classification of implant dentistry into straightforward, advanced, and complex, treatment with dental implants in the anterior maxilla is either an advanced or complex procedure. ${ }^{6}$ The SAC classification system has restorative and surgical components, which can be influenced by modifying factors on the basis of individual clinical situations.

"Esthetic Risk Assessment (ERA) analysis" is a pretreatment assessment tool that uses clinical factors to evaluate the risk of achieving an esthetic result based on known surgical and restorative approaches in a given clinical scenario. ${ }^{7}$ Esthetic risk factors should be determined directly with the patient before starting the treatment to avoid any posttreatment outcomes that does not meet the high expectations of the patient. The more high-risk categories the patient falls into, the more conservative the surgical and restorative approaches should be. ${ }^{8}$

\begin{abstract}
${ }^{1,4}$ Department of Preventive Dentistry, Faculty of Dentistry, Jordan University of Science and Technology, Irbid, Jordan

${ }^{2}$ Department of Oral Medicine and Periodontology, College of Dentistry, Qassim University, Qassim, Kingdom of Saudi Arabia

${ }^{3}$ Department of Prosthetic Dentistry, Jordan University of Science and Technology, Irbid, Jordan

Corresponding Author: Rola A Habashneh, Department of Preventive Dentistry, Faculty of Dentistry, Jordan University of Science and Technology, Irbid, Jordan, e-mail: rolaperio@yahoo.com

How to cite this article: Habashneh RA, Walid MA, et al. Socket-shield Technique and Immediate Implant Placement for Ridge Preservation: Case Report Series with 1-year Follow-up. J Contemp Dent Pract 2019;20(9):1108-1117.
\end{abstract}

Source of support: Nil

Conflict of interest: None

Clinical research is concerned about reducing treatment time, achieving optimum hard and soft tissue esthetics and improving patient's satisfaction. ${ }^{9-12}$

Several parameters must be considered to reach the Esthetic success. "White" esthetic parameters are related to the color and morphology of teeth, while "pink" esthetic parameters are related to the form, color, and features of the adjacent gingiva. ${ }^{13}$ Such esthetic challenges are pronounced after insertion of postextraction implants owing to volumetric changes that occur after the remodeling processes. ${ }^{14,15}$ Many studies showed that tooth extraction is followed by dimensional changes of the alveolar ridge. ${ }^{16-19}$ These changes are more dramatic in the buccal side 
of the socket. ${ }^{19}$ An estimated $2 \mathrm{~mm}$ thickness of residual buccal bone should exist at least at the surgical site after tooth extraction to obtain a successful restoration, and some authors reported that such thickness is often lower before the event of tooth extraction. ${ }^{20,21}$ The horizontal bone resorption resulting from tooth extraction is a physiological process that can be only partially countered. The alterations in the socket dimensions after extraction appear to be related to many biological mechanisms, among which the main role is played by the loss of the vascular support from the periodontal ligament. ${ }^{22-24}$

To overcome these dimensional changes, several methods were tried, including immediate implants ${ }_{,}^{25}$ grafting ${ }^{26}$ and barrier membranes. ${ }^{27}$ Efforts were directed toward proposing guided bone regeneration (GBR) procedures. ${ }^{28}$ It was reported that soft tissue volume contraction is often related to this type of surgical procedures. ${ }^{29}$ Mucogingival surgeries that aim to increase gingival volume, such as connective tissue grafts, often resulted in $30 \%$ soft tissue volumetric contraction. ${ }^{30}$ Therefore, it can be concluded that none of these methods was able to fully prevent volumetric changes of peri-implant hard and soft tissues over time. ${ }^{31}$

Socket ridge preservation or socket-shield technique or partial root retention protocol seems to show positive results although it has not been documented sufficiently. In this case series report, implants were placed immediately after extraction of the teeth presented with a hopeless prognosis utilizing the socket-shield technique, and some cases were followed up for some time and showed stable esthetic and functional outcomes.

\section{Case Description}

\section{Preoperative Assessment}

Five male patients aged between 20- and 54-year-old presented with a non-restorable teeth in the esthetic zone were treated using the socket-shield protocol and were followed up afterwards. Restorability was determined based on either periodontic or prosthodontic points of view. Some of the teeth included were nonrestorable owing to destructive caries, with others due to coronal or radicular fractures. Figures $1 \mathrm{~A}$ and $\mathrm{B}$ show the preoperative presentation for some cases prior to the tooth extraction.

All patients included were healthy and non-smokers. Initial clinical and radiographic examination showed that most patients had a sound, caries-free adjacent teeth. Periodontal examination showed that most patients had mild plaque-induced gingivitis. Most patients had high functional and esthetic demands.

Preoperative cone beam CT scans were obtained for all patients. Good interproximal bone levels and all socket walls were present in all cases analyzed. Figures $1 C$ and $D$ show the preoperative cone beam CT scan taken for some cases illustrating the dimensions of the bone present prior to extraction.

Several treatment options were discussed with each patient regarding best replacement method of the non-restorable tooth; all risks and benefits of each option were illustrated thoroughly. Options mostly discussed were conventional 3 units bridge, resinbonded bridge, and implant-supported crown restoration. All included patients decided to go for an implant-supported crown and signed a consent for that.

\section{Socket-shield Technique and Immediate Implant Placement}

To preserve as much as hard and soft tissue as possible, an immediate post-extraction implant in combination with partial extraction therapy (socket shield) was done for all patients.
Almost, same surgical technique was implemented. Following local anesthesia, the crown, if exists, was hemisected by a coarse bur, then the root was dissected in a mesiodistal direction along the long axis down to the apex using a long shank root resection bur (Komet Dental, Germany) coupled to a hydrated high-speed handpiece. The root was separated into buccal and palatal fragments. A periotome (Periotome \#1, Nordent, USA) was later inserted between the socket wall and the palatal fragment of the root and used to severe the periodontal attachment connecting the palatal fragment to the socket. The palatal fragment was removed with high caution keeping the buccal segment unmanipulated and attached to the buccal bone. Using a long shank round diamond bur (Komet Dental, Germany), the buccal segment was reduced to $1 \mathrm{~mm}$ supracrestally by careful preparation apico-coronally and mesio-distally creating a concave contour. Curettage was performed in the extraction socket and a copious saline irrigation followed to remove any infectious remnants. The stability of the buccal shield was checked with a sharp probe. The buccal socket shield was then ready. Figures $2 \mathrm{~A}$ and $B$ show the socket-shield preparation done in some cases after the removal of palatal fragment and keeping the buccal one along with its attachment apparatus.

In one of the cases, an esthetic flap was raised to remove the apex of the buccal root (Fig. 2C). The root was sectioned in the mesiodistal direction into buccal and palatal fragments. The two roots were later separated from the furcation area and a periotome was used to severe the periodontal attachment connecting the palatal fragment of the buccal root and the buccal fragment of the palatal root from the inter-radicular bone. This procedure created two shields (buccal and palatal) (Fig. 2D). The esthetic flap was sutured with a 5-0 polyglycolic acid suture (Fig. 2E).

Following sequential osteotomy drilling, implants were placed. Several implant systems were used such as BIOHORIZON tapered Laser-Lok ${ }^{\circledast}$, NobelActive, and Adin Touareg-S.

Diameters used ranged between 3.5 and $4.2 \mathrm{~mm}$, while lengths used ranged between 13 and $16 \mathrm{~mm}$. A postoperative periapical radiograph was obtained for all implants placed. Figures $3 \mathrm{~A}$ and $B$ show implants placed in some cases in the palatal aspect of the socket with some contact with the socket shield retained buccally.

The gap between the implant and the shield was filled with a calciumphosphosilicate synthetic bone grafting material NovaBone ${ }^{\circledast}$. Figure $3 C$ show the bone graft used to fill the gap between the implant and the shield.

In one of the cases, following pilot drilling of the implant site, osteotomy was prepared by oseodensification of the bone using Densah Bur 2.5 (DENSAH BUR-G2 VS2228) to a depth of $17 \mathrm{~mm}$ from gingival margin, to adopt the platform of the implant at $4 \mathrm{~mm}$ below gingival margin. The implant inserted gained its stability from the bone apical to the tooth socket and no bone grafting material was placed. Figure 3D show the bone condensation done at the surgical site and the implant that was secured in place without the need for any grafting material.

A customized healing abutment was prepared at the chair side with an S-shaped emergence profile to support a coronal natural emergence profile of the tooth (Figs $4 \mathrm{~A}$ and B). A post-surgical periapical radiograph was taken to confirm the seating of the healing abutment (Fig. 4C).

For esthetic issues, a provisional cement retained resin-bonded bridge was fabricated in the lab and delivered the next day for one of the cases (Fig. 4D).

Patients were prescribed a preoperative antibiotic of $1 \mathrm{~g}$ augmentin (875 g amoxicillin and $125 \mathrm{~g}$ clavulanic acid) twice 

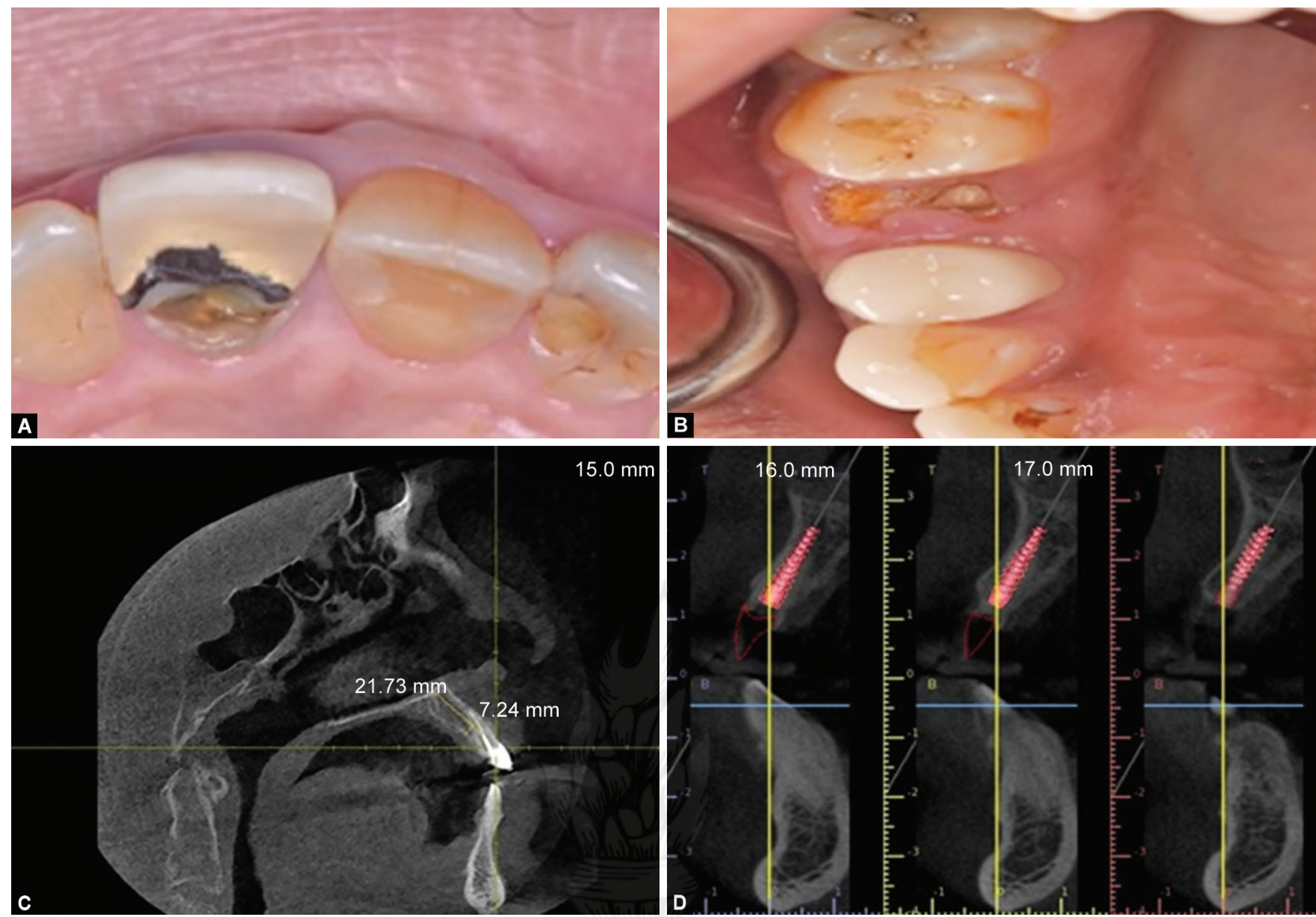

Figs 1A to D: (A) Preoperative photograph-a close-up occlusal view prior to tooth extraction; (B) Preoperative photograph-a pre-surgical occlusal view before tooth extraction; (C and D) Preoperative cone beam CT sagittal view showing the dimensions of the bone-the buccal bone wall is present

daily, and $400 \mathrm{mg}$ of ibuprofen three times daily the day before the surgery. Patients were advised to continue both medications for 4 days postoperatively.

Patients had follow-up visits after 6 weeks and 5 or 6 months. The soft tissue volume was well preserved (Fig. 5A). A cone beam CT scan was taken after 5 or 6 months of implant placement and showed that the buccal bone was well maintained (Fig. $5 \mathrm{~B})$. The intentional retention of the labial/buccal aspect of the root preserved the tissues on the implant site. The healing was uneventful, and the esthetic result was satisfactory (Fig. 5C).

Patients were included in a plaque control regimen, which consisted of oral hygiene instructions and professional plaque control throughout follow-up appointments.

\section{Prosthetic Reconstruction}

The healing abutment was removed after 5 or 6 months and the implant site was rinsed with $0.2 \%$ chlorhexidine mouthwash.

A closed-tray (Figs 6A and B) or open-tray (Figs 6C and D) impression posts of the same implant platform were secured in place and a periapical radiograph was taken to ensure complete seating. Impression posts were customized to copy the emergence profile created by the customized healing abutment. Stock trays were tried then painted using an adhesive and an implant-level closed-tray or open-tray (pick-up) impressions were taken using the 1-step vinyl polysiloxane light-putty impression technique. Light-body impression material was injected around impression posts while putty impression material was loaded in the tray. Trays were removed from patient's mouth and checked for details. Lab analogues of matched sizes were secured to impression posts; impressions were disinfected and sent to the lab for pouring into type IV gypsum.

Casts were ditched, and dies were sectioned for the fabrication of implant supported single crowns. Prefabricated screw-retained titanium abutment (Variobase abutment, Straumann) were used as the metal substructure of the crown and were selected and secured to lab analogues on the casts.

Metal substructures with a hole for the screw retention were designed and anatomically reduced by $1 \mathrm{~mm}$ to allow for porcelain veneering. Metal substructures were finished and checked for fitting. Hand-layering of glass ceramic was done on the surface, producing the full anatomy of the crowns, being supported in all areas by metal substructures. Porcelain fused to metal crowns were then polished and sent to the clinic for try-in.

Titanium abutments were transferred to patient's mouth in the same position and angulation on the cast and were secured in place. The crowns were then transferred to patient's mouth and checked for proximal contacts and fit and a periapical radiograph was taken to ensure complete seating. 

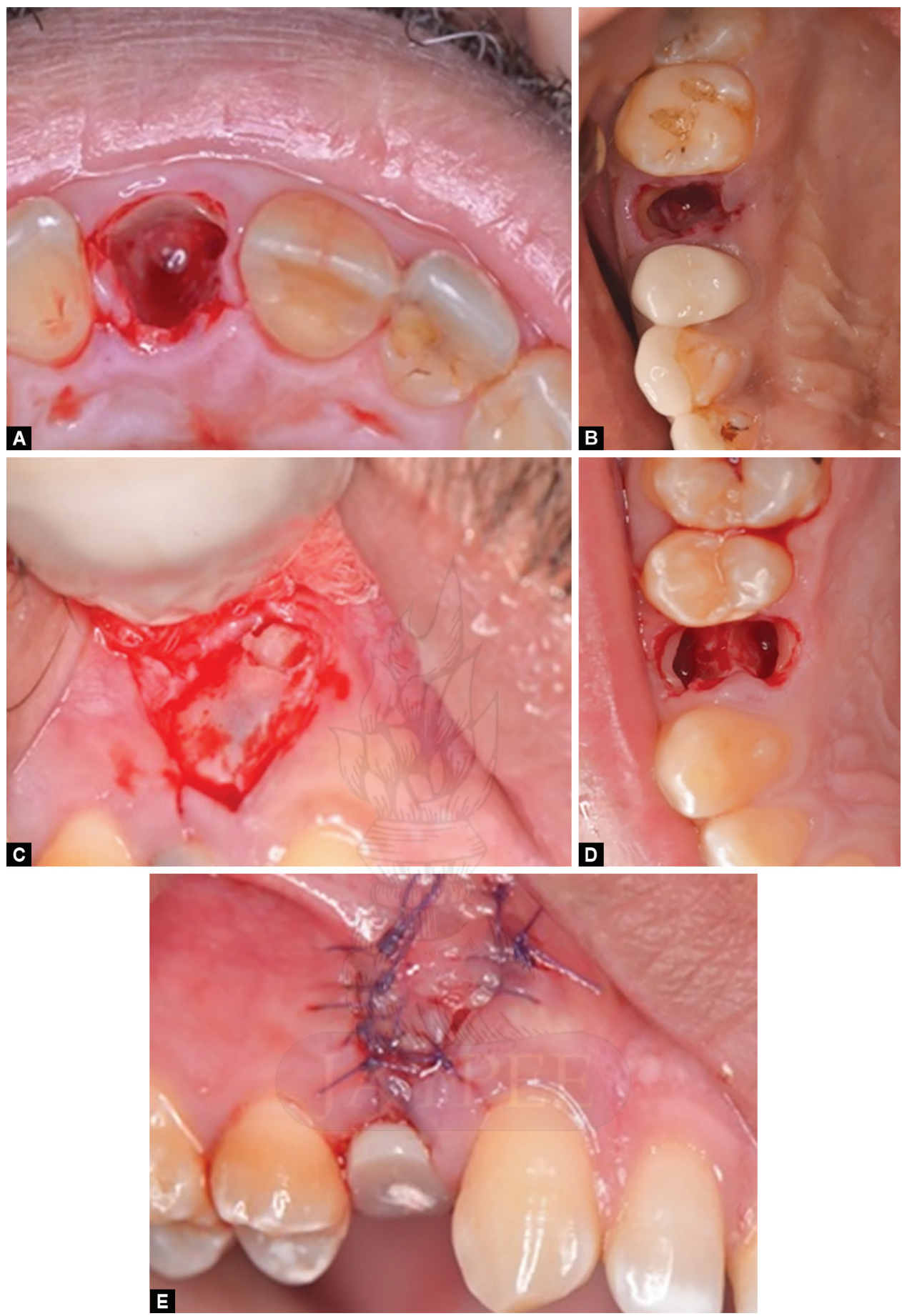

Figs $2 \mathrm{~A}$ to $\mathrm{E}:(\mathrm{A}$ and $\mathrm{B})$ The socket shield is prepared $1 \mathrm{~mm}$ above the buccal bone crest, smoothened, and rinsed; (C) Esthetic flap was raised to remove the apex of the buccal root; (D) Buccal and palatal socket shields prepared; (E) The flap is sutured with 5-0 polyglycolic acid sutures

Occlusion was then checked, centric occlusion at first then eccentric occlusion, using articulating paper (40 microns thick) and Shim stock foil (8 microns thick, folded into 4 folds). Occlusal adjustments were done using heatless rubber finishing burs. Crowns were sent back to the lab for final glazing and sandblasting of their fitting surface.

All laboratory procedures were conducted at a dental laboratory authorized by the manufacturers of the material systems.
Porcelain fused to metal crowns were cemented extraorally to titanium abutments using dual cured resin cement (RelyX Unicem, $3 \mathrm{M}$ ESPE) to make one-piece screw-retained single crown. Screwretained crowns and titanium abutments were inserted intraorally with $35 \mathrm{~N} \mathrm{~cm}$ torque and screw-access holes were restored with gutta percha (temporary stopping, GC) and light-polymerized composite resin (Filtek Z250, 3M ESPE). The crowns were free from any high occlusal spots (Figs $6 \mathrm{E}$ and $\mathrm{F}$ ). 

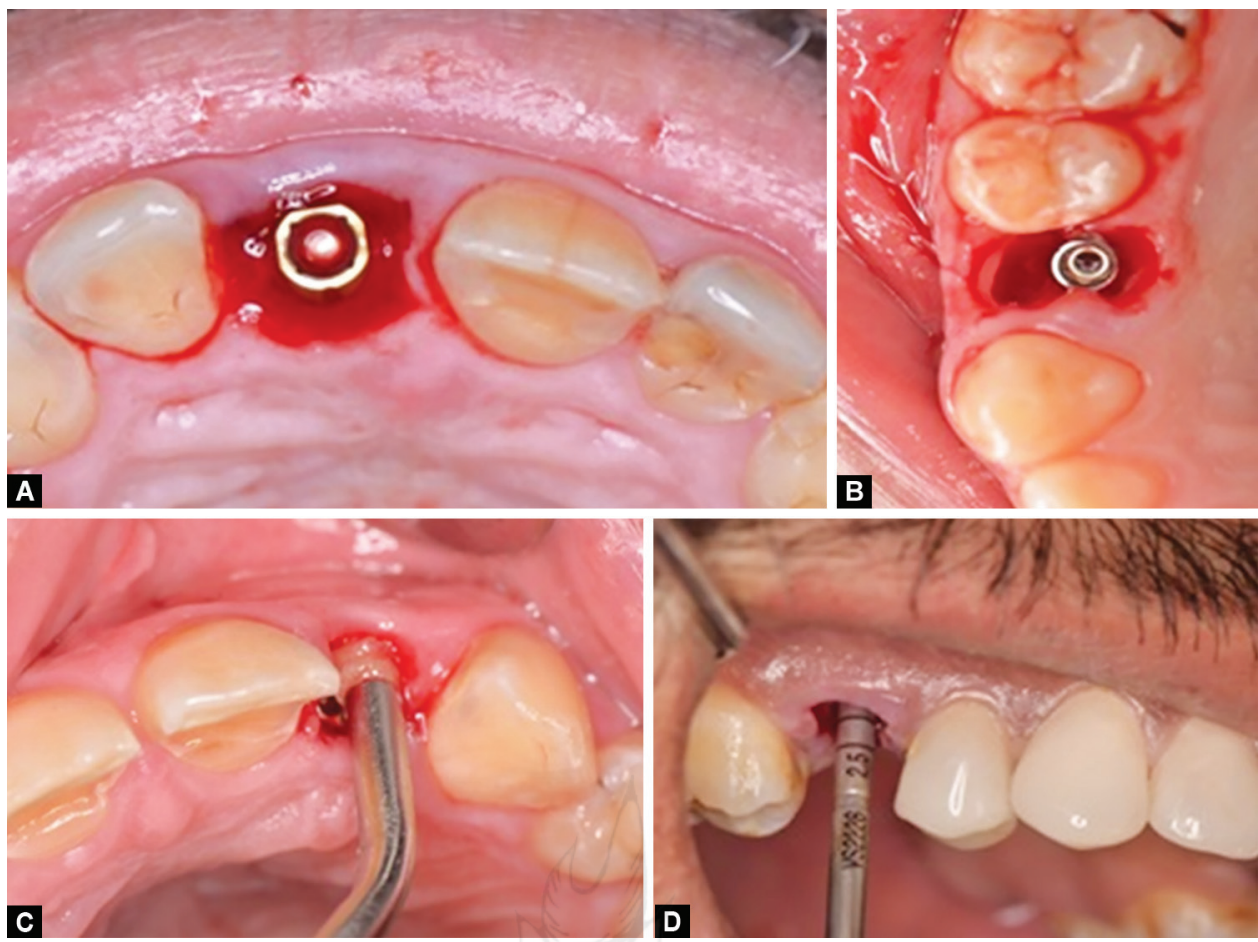

Figs $3 A$ to $D$ : (A and B) Occlusal view showing the implant placed in the palatal aspect of the socket with some contact with the socket shield retained buccally; (C) Bone graft filling the gap between the implant and the socket shield; (D) Bone condensation was performed on the surgical site
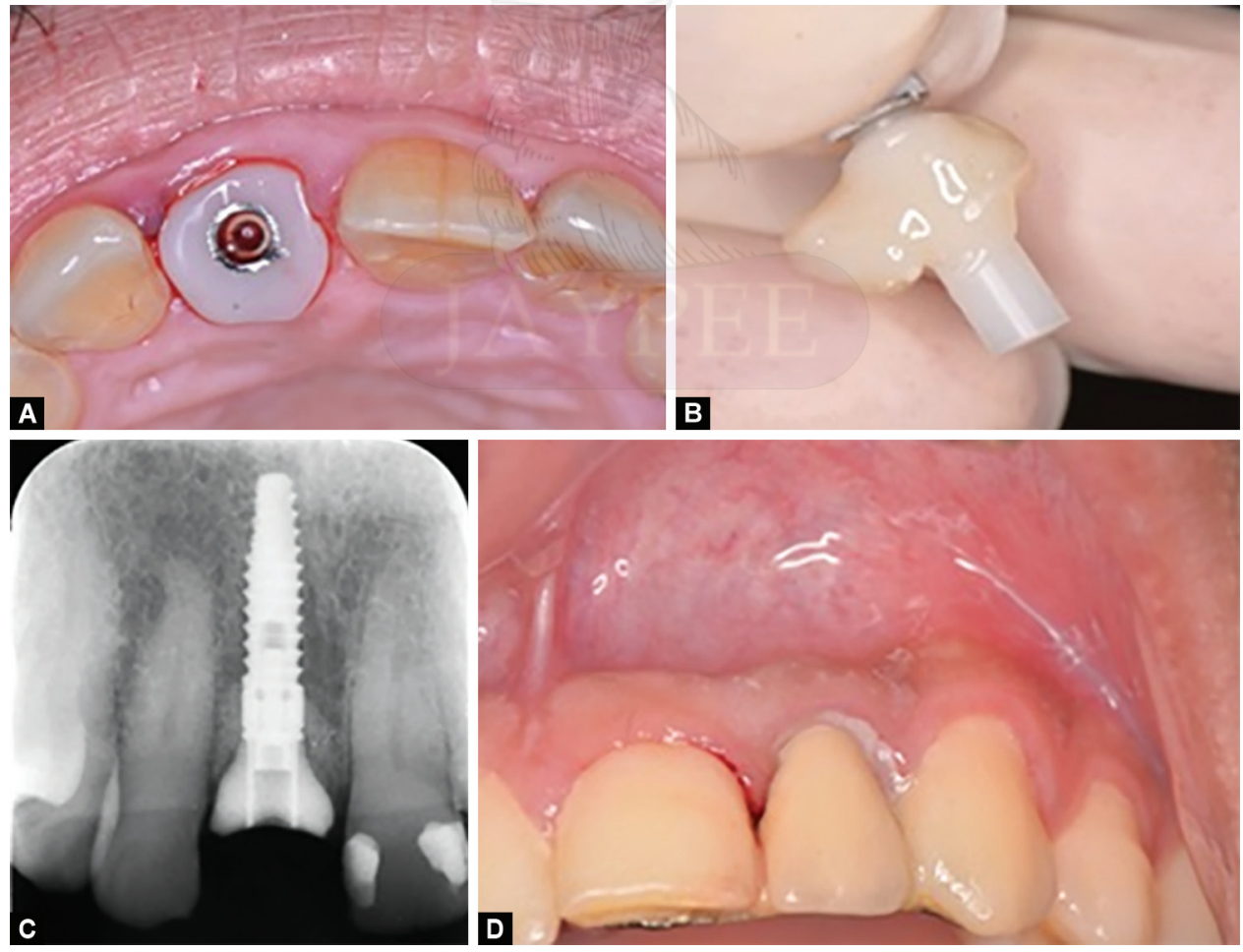

Figs 4A to D: (A) Customized healing abutment in place; (B) Customized healing abutment is ready for placement; (C) Radiographic appearance 6 weeks after the surgery; (D) 4D: provisional cement-retained resin-bonded prosthesis 

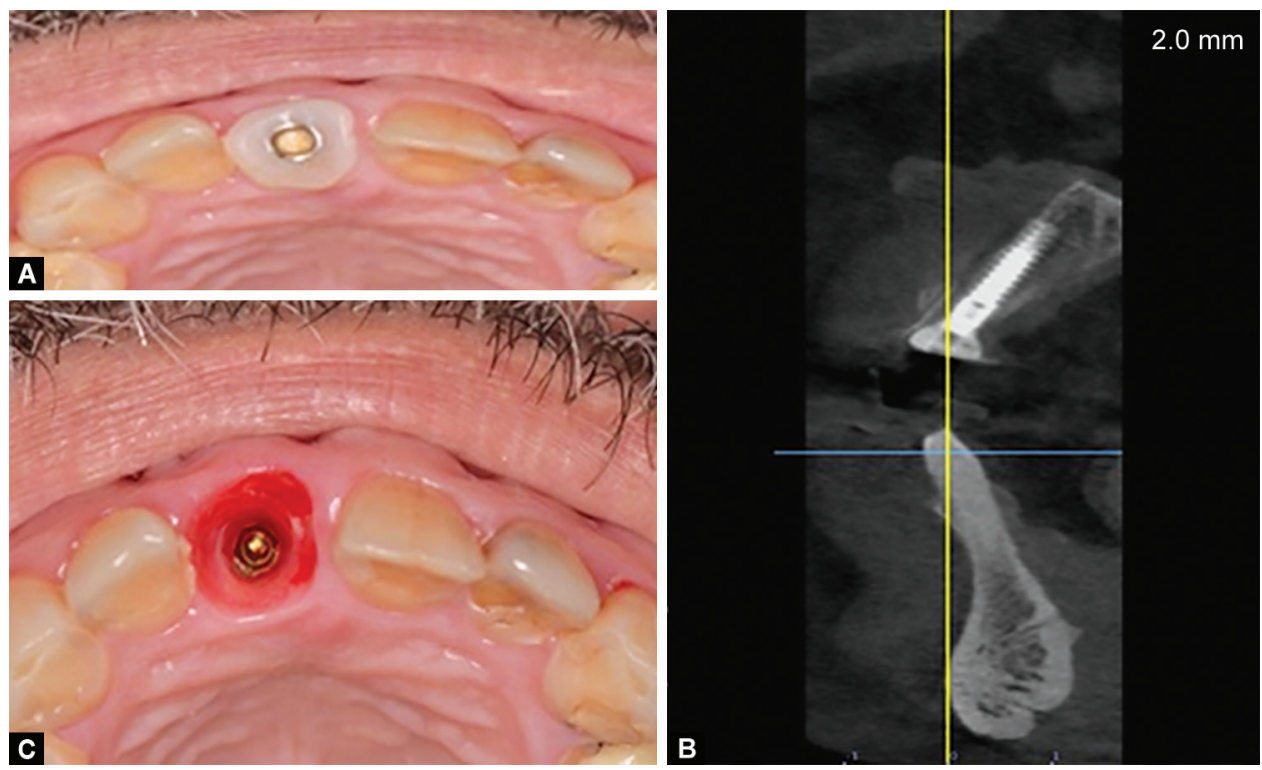

Figs 5A to C: (A) Clinical presentation 6 months after healing, occlusal view; (B) Cone beam CT showed a preserved buccal plate after 6 months; (C) Soft tissue healing after 6 months

Patients were again included in a plaque control regimen, which consisted of oral hygiene instructions and professional plaque control throughout follow-up appointments. One-year postoperative assessment showed no complications (Figs $6 \mathrm{G}$ and $\mathrm{H}$ ).

\section{Discussion}

This case series is in harmony with the current literature that supports the socket-shield technique. A case report by Filippi et al. showed that decoronation of an ankylosed tooth preserved the alveolar bone prior to implant placement. ${ }^{32}$ Reames et al. showed that the bone was formed even coronal to the level of amputated and submerged roots in dogs, which suggests that retained roots could enable vertical bone growth as well. ${ }^{33}$ Salama et al. reported that the root submergence technique (RST) maintains natural attachment of the tooth in a pontic site and thus aids in the creation of esthetic restorations in multiple-tooth-replacement cases. ${ }^{34}$ Davarpanah and Szmulker-Moncler reported a case series in which implants came in contact with ankylosed roots without any pathological sign after $12-42$ months after loading. ${ }^{35}$

In 2015, a systematic review concluded that immediate implant placement with immediate provisionlization in the esthetic zone results in excellent short-term outcomes in terms of implant survival and volumetric changes of peri-implant tissues. ${ }^{36}$ It was clear by then that good esthetics can be achieved by lingualized flapless implant placement into the fresh extraction socket, to preserve the buccal plate of the bone, ${ }^{37}$ while augmenting the gap with a slowly resorbable bone substitute to compensate for bone remodeling. ${ }^{38}$

Tapered implants were used in this case series because they minimize the incidence of rotational implant instability for the immediate implant placement and provisionlization. ${ }^{39}$ Implant diameter was chosen considering the buccal-palatal width rather than the mesiodistal distance to ensure stability of peri-implant soft and hard tissues. This diameter was less than $4.5 \mathrm{~mm}$ in the anterior maxilla. ${ }^{40} 3 \mathrm{D}$ implant position is crucial to achieve an esthetic outcome. In this case series, implants were placed palatally, avoiding the buccal wall, and creating an ideal gap between the implant and the buccal wall. This provided an ideal position to restore the implant and saved us a lot of biological complications. The presence of interproximal bone is mandatory to get some papilla around the restoration. ${ }^{41}$ The presence of the buccal bone will determine if a more a conservative approach can be implemented or not. According to Elian et al., all sockets treated in this case series were class I with a favorable prognosis toward immediate implant placement. ${ }^{42}$ Kan showed that type-I sockets is the most favorable and the most common. ${ }^{43}$

One of the critical factors for the esthetic success of single implant crowns is the ability to preserve or regenerate the interproximal papilla. ${ }^{44,45}$ Many factors influence the anatomical form of the papilla adjacent to single implant crowns such as alveolar crest height at adjacent teeth and maintenance of biological width. ${ }^{6}$

Many prosthetic and surgical protocols have been suggested to improve mucosal esthetic outcome of single implant crowns. Soft and hard tissue augmentation before, along with, or after implant placement, ${ }^{46-50}$ and surgical incision techniques that preserve or create papillae $e^{51,52}$ were reported in the literature. Enhancing soft tissue contour by using custom healing abutments and immediate provisional crowns to support the peri-implant mucosa and preserve its contour from any collapse during healing and for the long-term stability were described in many case reports, ${ }^{36,53}$ retrospective and prospective cohort studies. ${ }^{54-56}$ So, a suitable gingival contour is created using customized healing abutments. A customized impression post should be made for an accurate transfer of gingival contour to the cast for the proper fabrication of the restoration. ${ }^{57}$

Anatomically contoured healing abutments contain and protect slowly resorbing substitution grafts, resulting in hard and soft tissue volume preservation. Even in healed sites, customization of healing abutments demonstrated favorable outcomes compared to standard healing abutments. Upon customization, the soft tissue maturation closely resembles the natural root contour and allows for better generation of esthetic and functional implant supported restorations. ${ }^{58}$ 

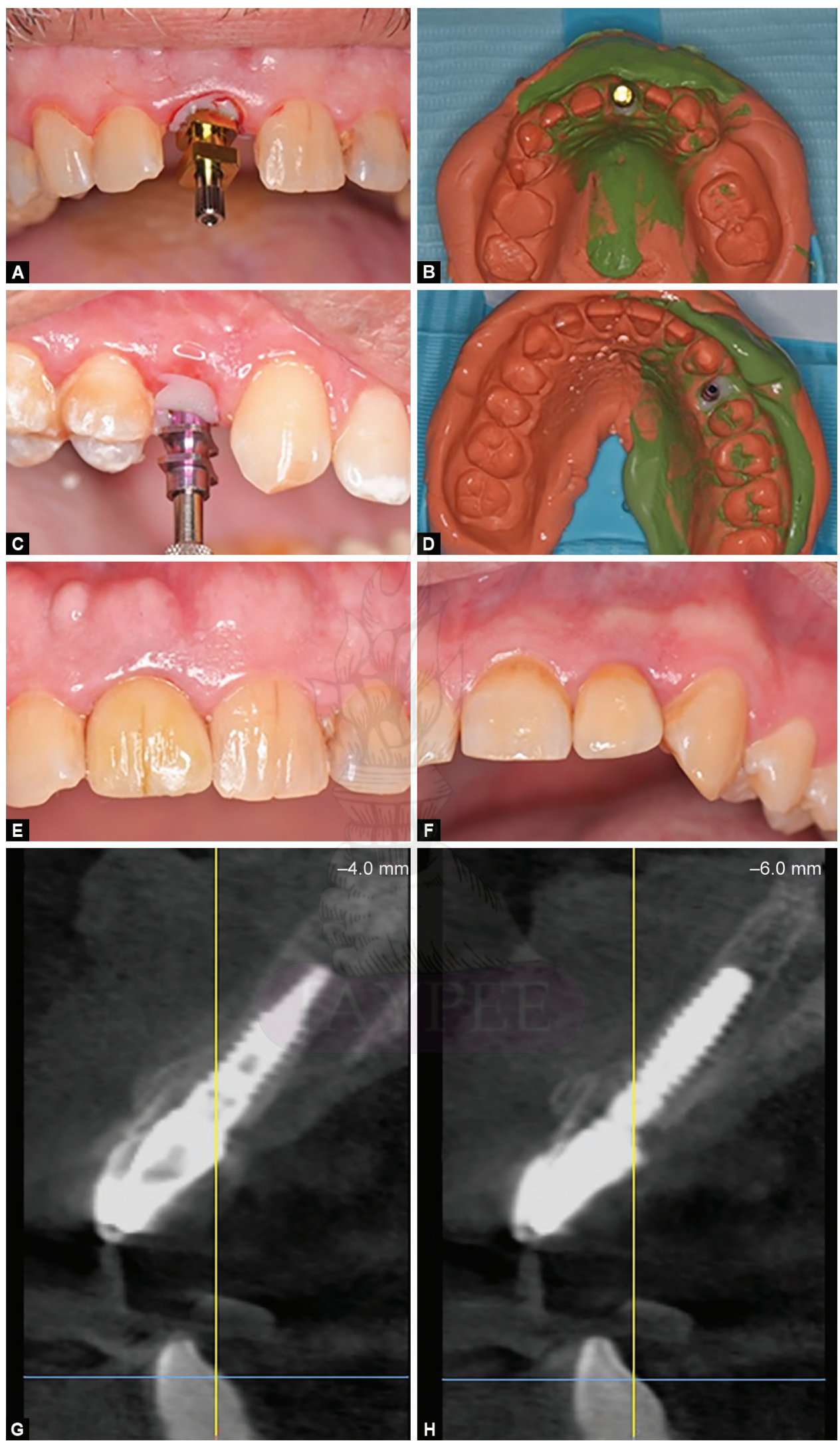

Figs $6 \mathrm{~A}$ to $\mathrm{H}$ : (A) Emergence profile was recorded around the closed-tray impression post; (B) Implant level closed tray 1-step vinyl polysiloxane light body-putty impression; (C) Emergence profile was recorded around the open-tray impression post; (D) Implant level open tray 1-step vinyl polysiloxane light body-putty impression; (E) Final screw-retained crown in the patient's mouth \#11, labial view; (F) Final screw-retained crown in the patient's mouth \#22, labial view; (G and H) Cone beam CT shows a preserved buccal plate after 1 year 
To make the position of gingival margin more predictable, Hurzeler et al. experimented a new surgical technique- "the socket-shield technique" - first on an animal model and then on humans in $2010 .^{59}$ The idea was to leave part of the root portion on the buccal side during the immediate insertion of the fixture. In this study, four implants were placed in the mandible of one beagle dog using the socket-shield technique. Two of the implants were placed intentionally in contact with the remaining part of the root while the other two were not touching it. All four implants osseointegrated and a physiologic periodontal ligament was present buccal to the root fragment. The two implants with a close contact with the root showed "new cementum" formation directly on the implant surface. No bone remodeling on the buccal side was detected. ${ }^{60}$ The purpose of this technique was to maintain a healthy periodontium and keep the crestal bone at the original level.

This technique has since been tested in multiple case reports, ${ }^{61-63}$ even in the presence of vertical root fractures and internal resorptions and it showed high clinical validity. ${ }^{64}$

A case report conducted by Kan et al. stated that maintaining inter-implant papillae is one of the most challenging tasks in anterior implant esthetics. ${ }^{62}$ Proximal socket-shield procedure with inter-implant papilla preservation are effective in maintaining bone level and dentogingival fibers attached to proximal supra-crestal cementum, thus preserving inter-implant papilla.

Gluckman et al. presented a case series of 14 sites in 10 patients treated with socket shield to develop pontic sites. ${ }^{65}$ The sockets received different closure techniques. An estimated 5 sockets were subjected to buccal flap advancement and showed complete healing, 3 sockets were left open and all of them showed incomplete healing with exposure of the shield requiring surgical closure, 1 was subject to placement of cytoplast membrane and showed a wider band of attached gingiva, 3 were treated with the socket-seal technique and showed complete healing that took a longer time, and the last 2 sockets were closed by the means of free gingival graft and showed complete healing with excellent soft tissue contours. All patients were non-smokers and showed no periapical pathology. In this study, all sockets were additionally grafted with a xenographic bone particulate (Gen-Os).

Gluckman et al. reported a case in which the soft tissue contours of the implant site (left central incisor) remained comparable to the adjacent central incisor a year after the socket-shield therapy. ${ }^{66}$

Abitbol et al. reported a one-year retrospective study of 20 patients (four of which were smokers) treated in 2 clinics with different types of implants: NobelActive (Nobel Biocare ${ }^{\circledR}$ ), Certain Prevail, T3 Parallel Walled (Biomet $\left.3 i^{\circledR}\right) .{ }^{67}$ All implants were integrated with no signs of inflammation after one year. However, two complications occurred: a probing pocket of $8 \mathrm{~mm}$ in a root and the exposition of a root in another case. Pink esthetic score was evaluated, which showed an improvement in most cases in comparison to the initial situation.

A case report of 5 years was reported by Mitsias et al. ${ }^{68}$ In this study, histologic evidence was also reported as the patient had lost the implant owing to trauma. The buccal plate was maintained without any resorption and a healthy periodontal ligament could be seen between the root fragment and the bone. The implant showed osteointegration with a $76.2 \%$ bone-to implant contact. The space between the implant and the root fragment was filled by a mature bone in the apical and middle thirds, while the coronal third was filled with non-infiltrated connective tissue. Cementum was detected in contact with the implant at the apical part.
A case control study by Abadzhiev et al. included placing 26 implants in 25 patients (16 implants were placed in a conventional immediate manner and 10 implants were placed using the socketshield technique). ${ }^{69}$ All cases were followed up within 2 years, and all implants were evaluated by X-rays, soft tissue volume, and esthetic evaluation by both the dentist and the patient. Bone loss and soft tissue loss were lower in the socket-shield group, while esthetic satisfaction was higher.

A systematic review by Gharpure and Bhatavadekar concluded that current evidence is not enough to recommend this technique and that further studies are needed as the literature contained only one (the aforementioned) case control study and many case reports. ${ }^{70}$ The present case report describes three consecutive cases in which a socket shield was applied as part of immediate implantation.

A retrospective case series of 10 consecutive patient was done by Baumer et al. ${ }^{64}$ Impressions were made before extraction of the teeth and after 5 years of implant placement. 3D-scans of casts were digitally superimposed for quantitative evaluation of periimplant facial contour and gingival recessions. Volumetric analysis showed minimal contour changes from the date of extraction till after 5 years and it was suggested that socket-shield technique is a minimally invasive technique with high esthetic outcomes and effective preservation of peri-implant contours.

Another prospective randomized clinical trial was conducted to evaluate survival and success rate of conventional post-extraction implant placement and socket-shield implant placement in the esthetic zone. ${ }^{71}$ Implant survival rate of $100 \%$ was found in both groups at 3 years. Socket-shield implant placement resulted in better values for marginal bone level and pink esthetic scores. Socket-shield technique was described as a safe surgical protocol that allows for better esthetic outcomes.

Our results showed that the socket-shield technique can preserve the contour of the ridge. While histological examination is necessary to confirm the preservation of the buccal plate, the clinical outcome is satisfactory from an esthetic point of view.

Immediate implant placement is a predictable procedure in terms of osteointegration. ${ }^{72}$ However, the bone loss in the socket is not altered by the immediate placement of implants. ${ }^{25}$ Soft tissue grafting or guided bone regeneration (GBR) could partly alter the dimensional changes but not stop it. ${ }^{73}$

The socket-shield technique is a minimally invasive procedure that preserves hard and soft tissues. It has not only been used with dental implants but has been also used for pontic sites. ${ }^{16}$

The use of this technique in areas of esthetic demands seems to be reasonable and lead to more esthetic outcomes. However, more trials including case-control studies are needed.

\section{Clinical Significance}

This case report series demonstrate that improved buccal contour stability and better esthetic outcomes can be achieved with the socket-shield technique and immediate implant placement.

\section{References}

1. Jemt T, Pettersson P. A 3-year follow-up on single implant treatment. J Dent 1993;21:203-208. DOI: 10.1016/0300-5712(93)90127-C.

2. Henry PJ, Laney WR, et al. Osseointegrated implants for single-tooth replacement: A prospective 5-year multicenter study. Int J Oral Maxillofac Implants 1996;11:450-455. 
3. Jemt T. Modified single and short-span restorations supported by osseointegrated fixtures in the partially edentulous jaw. J Prosthet Dent 1986;55:243-246. DOI: 10.1016/0022-3913(86)90352-5.

4. Goodacre CJ, Bernal G, et al. Clinical complications with implants and implant prostheses. J Prosthet Dent 2003;90:121-132. DOI: 10.1016/ S0022-3913(03)00212-9.

5. Palmer RM, Smith BJ, et al. A prospective study of Astra single tooth implants. Clin Oral Implants Res 1997;8:173-179. DOI: 10.1034/j.16000501.1997.080303.x.

6. Buser D, Martin W, et al. Optimizing esthetics for implant restoration in the anterior maxilla: anatomic and surgical considerations. Int J Oral Maxillofac Implants 2004;19(Suppl):43-61.

7. Martin W, Morton C, et al. Pre-operative analysis and prosthetic treatment planning in esthetic implant dentistry. Buser D, Belser $\mathrm{U}$, et al. ITI Treatment Guide I: Implant Therapy in the Esthetic Zone: Single Tooth Replacements. New Malden, Surrey, UK: Publishing Co Ltd; 2007. pp. 9-24.

8. Buser D, Halbritter $S$, et al. Early implant placement with simultaneous guided bone regeneration following single-tooth extraction in the esthetic zone: 12-month results of a prospective study with 20 consecutive patients. J Periodontol 2009;80:152-162. DOI: 10.1902/ jop.2009.080360.

9. Belser U, Buser D, et al. Consensus statements and recommended clinical procedures regarding esthetics in implant dentistry. Int J Oral Maxillofac Implants 2004;19(Suppl):73-74.

10. Gapski R, Wang H-L, et al. Critical review of immediate implant loading. Clin Oral Implants Res 2003;14:515-527. DOI: 10.1034/j.16000501.2003.00950.x.

11. Aparicio C, Rangert B, et al. Immediate/Early loading of dental implants: a report from the Sociedad Espanola de Implantes World Congress consensus meeting in Barcelona, Spain 2002. Clin Implant Dent Relat Res 2003;5:57-60. DOI: 10.1111/j.1708-8208.2003. tb00183.x.

12. Attard NJ, Zarb GA. Immediate and early implant loading protocols: a literature review of clinical studies. J Prosthet Dent 2005;94:242-258. DOI: 10.1016/j.prosdent.2005.04.015.

13. Vermylen K, Collaert B, et al. Patient satisfaction and quality of single-tooth restorations. Clin Oral Implants Res 2003;14:119-124. DOI: 10.1034/j.1600-0501.2003.140116.x.

14. Tonetti MS, Cortellini P, et al. Immediate vs delayed implant placement after anterior single tooth extraction: the timing randomized controlled clinical trial. J Clin Periodontol 2017;44:215-224. DOI: 10.1111/jcpe.12666.

15. Figliuzzi MM, Giudice $A$, et al. Postextractive implants in aesthetic areas: evaluation of perimplant bone remodeling over time. Ann Stomatol (Roma) 2015;6:29-34. DOI: 10.11138/ads/2015.6.1.029.

16. Amler $\mathrm{M}$, Johnson $\mathrm{P}$, et al. Histologic and histochemical investigation of human alveolar socket healing in undisturbed extraction wounds. J Am Dent Assoc 1960;61:46-48. DOI: 10.14219/jada.archive.1960.0152.

17. Araújo MG, Lindhe J. Dimensional change alterations following tooth extraction. An experimental study in the dog. J Clin Periodontol 2005;32:212-218.

18. Schropp L, Wenzel A, et al. Bone healing and soft tissue contour changes following single-tooth extraction: a clinical and radiographic 12-month prospective study. Int J Periodontics Restorative Dent 2003;23:313-323.

19. Pietrokovski J, Massler M. Alveolar ridge resorption following tooth extraction. J Prosthet Dent 1967;17:21-27. DOI: 10.1016/00223913(67)90046-7.

20. Buser D, Chappuis V, et al. Implant placement post extraction in esthetic single tooth sites: when immediate, when early, when late? Periodontology 2000 2017;73:84-102. DOI: 10.1111/prd.12170.

21. Fu JH, Yeh CY, et al. Tissue Biotype and Its Relation to the Underlying Bone Morphology. J Periodontol 2010;81:569-574. DOI: 10.1902/ jop.2009.090591.

22. Van der Weijden F, Dell'Acqua F, et al. Alveolar bone dimensional changes of post-extraction sockets in humans: a systematic review. J Clin Periodontol 2009;36:1048-1058. DOI: 10.1111/j.1600051X.2009.01482.x.

23. Wang RE, Lang NP. Ridge preservation after tooth extraction. Clin Oral Implants Res 2012;23(suppl 6):147-156. DOI: 10.1111/j.16000501.2012.02560.x.

24. Kotsakis G, Chrepa V, et al. Flapless alveolar ridge preservation utilizing the"socket-plug" technique: clinical technique and review of the literature. J Oral Implantol 2014;40:690-698. DOI: 10.1563/ AAID-JOI-D-12-00028.

25. Botticelli $D$, Berglundh $T$, et al. Hard tissue alterations following immediate implant placement in extraction sites. J Clin Periodontol 2004;31:820-828. DOI: 10.1111/j.1600-051X.2004.00565.x.

26. Carmagnola $D$, Adriaens $P$, et al. Healing of human extraction sockets filled with Bio-Oss. Clin Oral Implants Res 2003;14:127-143. DOI: 10.1034/j.1600-0501.2003.140201.x.

27. Lekovic V, Carmargo P, et al. Preservation of alveolar bone in extraction sockets using bioresorbable membranes. J Peirodontol 1998;69:1044-1049. DOI: 10.1902/jop.1998.69.9.1044.

28. Vignoletti F, Sanz M. Immediate implants at fresh extraction sockets: from myth to reality. Periodontology 2000 2014;66:132-152. DOI: 10.1111/prd.12044.

29. Donos N, Mardas N, et al. Clinical outcomes of implants following lateral bone augmentation: systematic assessment of available options (barrier membranes, bone grafts, split osteotomy). J Clin Periodontol 2008;35(8 suppl):173-202. DOI: 10.1111/j.1600-051X. 2008.01269.x.

30. Studer SP, Lehner C, et al. Soft tissue correction of a singletooth pontic space: a comparative quantitative volume assessment. J Prosthet Dent 2000;83:402-411. DOI: 10.1016/S0022-3913(00)70034-5.

31. Troiano G, Zhurakivska K, et al. Combination of bone graft and resorbable membrane for alveolar ridge preservation: a systematic review, meta-analysis and trial sequential analysis. J Periodontol 2017; 1-17. DOI: 10.1902/jop.2017.170241.

32. Filippi A, Pohl Y, et al. Decoronation of an ankylosed tooth for preservation of alveolar bone prior to implant placement. Dent Traumatol 2001;17:93-95. DOI: 10.1034/j.1600-9657.2001.017002093.x.

33. Reames RL, Nickel JS, et al. Clinical, radiographic and histologic study of endodontically treated retained roots to preserve alveolar bone. J Endod 1975;1:367-373. DOI: 10.1016/S0099-2399(75)80212-3.

34. Salama M, Ishikawa I, et al. Advantages of the root submergence technique for pontic site development in esthetic implant therapy. Int J Periodontics Restorative Dent 2007;27:521-527.

35. Davarpanah M, Szmulker-Moncler S. Unconventional implant treatment I. Implant placement in contact with ankylosed tooth fragments. A series of five case reports. Clin Oral Implants Res 2009;20:851-856. DOI: 10.1111/j.1600-0501.2008.01653.x.

36. Slagter KW, den Hartog L, et al. Immediate placement of dental implants in the esthetic zone: a systematic review and pooled analysis. J Periodontol 2014;85:e241-e250. DOI: 10.1902/jop.2014.130632.

37. Lee EA, Gonzales MO, et al. Lingualized Flapless Implant Placement into Fresh Extraction Sockets Preserves Buccal Alveolar Bone: A Cone Beam Computed Tomography Study. Int J Periodontics Restorative Dent 2014;34:61-68. DOI: 10.11607/prd.1807.

38. Kasugai S, Le B, et al. Effect of Buccal Gap Distance on Alveolar Ridge Alteration After Immediate Implant Placement. Implant Dent 2015;24:70-76. DOI: 10.1097/ID.0000000000000194.

39. Kan J, Roe P, et al. Effects of implant morphology on rotational stability during immediate implant placement in the esthetic zone. Int J Oral Maxillofac Implants 2015;30:667-670. DOI: 10.11607/jomi.3885.

40. Canullo L, lannello G, et al. Impact of implant diameter on bone level changes around platform switched implants: preliminary results of 18 months follow-up a prospective randomized match-paired controlled trial. Clin Oral Implants Res 2012;23:1142-1146. DOI: 10.1111/j.1600-0501.2011.02297.x.

41. Kan J, Rungcharassaeng K. Interimplant papilla preservation in the esthetic zone: a report of six consecutive cases. Int J Periodontics Restorative Dent 2003;23:248-259. 
42. Elian N, Cho SC, et al. A simplified socket classification and repair technique. Pract Proced Aesthet Dent 2007;19:99-104.

43. Kan J, Rungcharassaeng $\mathrm{K}$, et al. Facial gingival stability following immediate placement and provisionalization of maxillary anterior single implants: a 2- to 8-year follow-up. Int J Oral Maxillofac Implants 2011;26:179-187.

44. Jemt T. Regeneration of gingival papillae after single-implant treatment. Int J Periodont Rest Dent 1997;17:327-333.

45. Priest G. Predictability of soft tissue form around single-tooth implant restorations. Int J Periodont Rest Dent 2003;23:19-27.

46. Cobb GW, Reeves GW, et al. Guided tissue healing for single-tooth implants. Compend Contin Educ Dent 1999;20:571-581.

47. Grunder U. Stability of the mucosal topography around single-tooth implants and adjacent teeth: 1-year results. Int J Periodont Rest Dent 2000;20:11-17.

48. Sclar AG. Soft tissue and esthetic considerations in implant therapy. Bywaters LC. Soft Tissue and Esthetic Considerations in Implant Therapy. Chicago, IL: Quintessence; 2003. pp. 144-163.

49. Jemt T, Lekholm U. Measurements of buccal tissue volumes at singleimplant restorations after local bone grafting in maxillas: a 3-year clinical prospective study case series. Clin Implant Dent Relat Res 2003;5:63-70. DOI: 10.1111/j.1708-8208.2003.tb00185.x.

50. Chen ST, Darby IB, et al. A prospective clinical study of bone augmentation techniques at immediate implants. Clin Oral Implants Res 2005;16:176-184. DOI: 10.1111/j.1600-0501.2004.01093.x.

51. Tarnow DP, Eskow RN, et al. Aesthetics and implant dentistry. Periodontology 2000 1996;11:85-94. DOI: 10.1111/j.1600-0757.1996. tb00186.x.

52. Choquet $\mathrm{V}$, Hermans $\mathrm{M}$, et al. Clinical and radiological evaluation of the papilla level adjacent to single-tooth dental implants. A retrospective study in the maxillary anterior region. J Periodontol 2001;72:1364-1371. DOI: 10.1902/jop.2001.72.10.1364.

53. Cooper LF, Raes F, et al. Immediate provisionalization of dental implants placed in healed alvelar ridges and extraction sockets: a 5-year prospective evaluation. Int J Oral Maxillofac Implants 2014;29(3):709-717. DOI: 10.11607/jomi.3617.

54. Jemt $\mathrm{T}$. Restoring the gingival contour by means of provisional resin crowns after single-implant treatment. Int J Periodont Rest Dent 1999;19:21-29.

55. Henriksson K, Jemt T. Measurements of soft tissue volume in association with single-implant restorations: a 1-year comparative study after abutment connection surgery. Clin Implant Dent Relat Res 2004;6:181-189. DOI: 10.1111/j.1708-8208.2004.tb00034.x.

56. Block $M$, Finger l, et al. Single tooth immediate provisional restoration of dental implants: technique and early results. J Oral Maxillofac Surg 2004;62:1131-1138. DOI: 10.1016/j.joms.2004.05.115.

57. Harshakumar K, Deepthi VS, et al. Customized healing abutment for enhancing pink aesthetics in implants. J Dent Implants 2013;3: 172-176. DOI: 10.4103/0974-6781.118862.

58. Stumpel LJ, Wadhwani C. A Customized Healing Abutment for Immediate and Delayed Implant Cases. Compend Contin Educ Dent 2017;38:672-678.
59. Hurzeler MB, Zuhr O, et al. The socket-shield technique: a proofof-principle report. J Clin Periodontol 2010;37:855-862. DOI: 10.1111/j.1600-051X.2010.01595.x.

60. Baumer D, Zuhr O, et al. The socket-shield technique: first histological, clinical, and volumetrical observations after separation of the buccal tooth segment-a pilot study. Clin Implant Dent Relat Res 2015;17:71-82. DOI: 10.1111/cid.12076.

61. Chen $\mathrm{CL}$, Pan $\mathrm{YH}$. Socket shield technique for ridge preservation: A case report. J Prosthodontics Implant 2013;2:16-21.

62. Kan J, Rungcharassaeng K. Proximal socket shield for interimplant papilla preservation in the esthetic zone. Int J Periodontics Restorative Dent 2013;33:e24-e31. DOI: 10.11607/prd.1346.

63. Wadhwani P, Goyal S, et al. Socket shield technique: a new concept of ridge preservation. Asian J Oral Health Allied Sci 2015;5:55-58. DOI: $10.1017 /$ S2044251314000083.

64. Baumer D, Zuhr O, et al. Socket shield technique for immediate implant placement-clinical, radiographic and volumetric data after 5 years. Clin Oral Implants Res 2017;28:1450-1458. DOI: 10.1111/ clr.13012.

65. Gluckman H, Du Toit J, et al. The pontic-shield: partial extraction therapy for ridge preservation and pontic site development. Int J Periodontics Restorative Dent 2016;36:417-424. DOI: 10.11607/ prd.2651.

66. Gluckman H, Du Toit J, et al. The socket-shield technique to support buccofacial tissues at immediate implant placement. Int Dent Afr 2015;5:6-14.

67. Abitbol J, Antoun $\mathrm{H}$, et al. Outcome of dental implant with the socket-shield technique: A retrospective study. Clin Oral Implants Res 2016;27(Suppl 13):530.

68. Mitsias M, Siormpas K, et al. The root membrane technique: Human histologic evidence after five years of function. Biomed Res Int 2017; 1-8. DOI: $10.1155 / 2017 / 7269467$.

69. Abadzhiev M, Nekov P, et al. Conventional immediate placement and immediate placement with socket-shield technique - which is better. Int J Clin Med Res 2014;1:176-180.

70. Gharpure A, Bhatavadekar N. Current evidence on the socket-shield technique: a systematic review. J Oral Implantol 2016;43:395-403. DOI: 10.1563/aaid-joi-D-17-00118.

71. Bramanti E, Norcia A, et al. Postextraction dental implant in the aesthetic zone, socket shield technique vs conventional protocol. J Craniofac Surg 2018;29:1037-1041. DOI: 10.1097/ SCS.0000000000004419.

72. Den Hartog L, Slatter JJ, et al. Treatment outcome of immediate, early and conventional single-tooth implants in the aesthetic zone: a systematic review to survival, bone level, soft-tissue, aesthetics and patient satisfaction. J Clin Periodontol 2008;35:1073-1086. DOI: 10.1111/j.1600-051X.2008.01330.x.

73. Esposito M, Grusovin MG, et al. The efficacy of various bone augmentation procedures for dental implants: a Cochrane systematic review of randomized controlled trials. Int J Oral Maxillofac Implants 2006;21:696-710. 